\title{
Determine Dietary Diversity and Its Relationship with Nutritional Status of Adolescents Studying in High Schools of Bagalkot
}

\author{
Lakshmavva Gondi*, Utalbasha Dhandargi**, Deelip S Natekar*** \\ *M.Sc. Nursing Final Year, Shri B.V.V.S Sajjalashree Institute of Nursing Sciences, Bagalkot, Karnataka \\ ${ }^{* *}$ Professor, Department of Community Health Nursing, Shri B.V.V.S Sajjalashree Institute of Nursing Sciences \\ Navanagar Bagalkot, Karnataka, India \\ *** Principal, Shri B.V.V.S, Sajjalashree Institute of Nursing Sciences, Navanagar, Bagalkot, Karnataka
}

Corresponding Author: Deelip S Natekar

DOI: https://doi.org/10.52403/ijshr.20220105

\begin{abstract}
Introduction: Dietary diversity is defined as the number of food groups or items consumed over a reference period. A good diverse diet is necessary to furnish the daily nutritional requirements of body. Inadequate dietary diversity is one of major public health problem and can result in unhealthy physical, emotional and psychological changes among adolescents. Objective of the study was to determine dietary diversity and its relationship with nutritional status of adolescents studying in high school.

Methods: A school-based cross-sectional study was conducted from March 12 to April 03, 2021, among a total of 120 adolescents, selected using the stratified random sampling technique. The study was conducted in Kalidas high school, Bagalkot. A structured and prepared questionnaire was used to collect baseline data. Dietary diversity was measured by Food and Nutrition Technical Assistance (FANTA) 2020 using the food items method. A multivariable binary logistic regression model was employed to identify the association of nutritional status and dietary diversity among adolescents.

Result: Mean age of sample was $15.14 \pm 0.81$ years. The mean height for age was 1.63 S.D \pm .880 S.D. The mean BMI for age $\mathrm{Z}$ score was $1.73 \mathrm{SD} \pm .579$ SD. The mean BMI for thinness $\mathrm{Z}$ score was $2.35 \mathrm{SD} \pm 1.301 \mathrm{SD}$. Logistic regression analysis revealed that there was no significant association $(\mathrm{P}<0.202)$ found between dietary diversity and nutritional status of adolescents.
\end{abstract}

Conclusion: The findings of this study showed that only one-third of both (boys and girls) have adequate dietary diversity. Low level of dietary diversification suggested points to the need for strengthening efforts targeting to improve the healthy dietary practice of adolescents by giving due attention to poor households and undernourished adolescents.

Key words: dietary diversity, nutritional status, adolescents, High school, unhealthy dietary pattern.

\section{INTRODUCTION}

Adolescents generally find that activities involving physical movement sports, dance and drama, are among the most pleasurable and gratifying activities. Ironically, the opportunities for participation in such activities have dwindled, because of compensation with the nutritional status of the body. The exploration of these sportive activities needs the adolescent with proper diet and nutritional status. If the adolescent is undernourished or over-nourished it will be difficult to move with the advancing world. $^{2}$

Adolescents form the future generation of a country. Adolescents' nutritional needs are critical for the well being of a society. Investing in nutrition throughout the life cycle will have both short-term and long term benefits of 
economic and social significance. It has been defined by the World Health Organization (WHO) as the period characterized by rapid physical growth, significant emotional, psychological and spiritual changes; and evolving personal relationships. Adolescence is recognized as a phase rather than a fixed time period in an individual's life. $^{3}$

One way to break the intergenerational cycle of malnutrition is to improve the nutrition of adolescent girls prior to conception. Adolescent health and nutrition are important issues which have not received the attention, it deserves in our country, especially in the context of a girl child. India has largest adolescent population in the world. Malnutrition, especially under-nutrition, is a major health problem affecting the development of children in many low- and middle-income countries. ${ }^{5}$

Healthy growth and development essentially need a balance diet of nutrients and vitamins which includes a variety of foods from different food groups. Nutrition is a main component of health and development. Healthy eating is related to lower risk of chronic disease. Dietary diversity and the amount of animal source foods that individual consumers are two commonly used measures for dietary quality. Healthy growth and development essentially need a balance diet of nutrients and vitamins which includes a variety of foods from different food groups like vegetables, fruits grains, and animal source foods. Dietary diversity can be measured at the household or individual level with regarding dietary factors that are associated with increased risk of chronic disease, nutritional advice promotes dietary diversity and reduce intake of non-Healthy food items such as fat, salt refined sugars. Monotonous diet based on starchy staples lack essential micronutrients and contribute to the burden of malnutrition and micronutrient deficiencies food-based strategies are prepared to meet micronutrient needs as a first priority. ${ }^{11}$
When it comes to adolescent malnutrition, adolescents in low-income families are more malnourished than those in high-income families. It is indeed necessary to determine the socio demographic factors that contribute to malnutrition among adolescents. The nutritional status is ultimately associated with dietary diversity of the adolescents; hence control of such factors in early life of a adolescents can contribute to healthy future of a adolescents. It is highly necessary to determine the socio demographic factors that contribute to adolescent nutritional status.

\section{MATERIALS AND METHODS}

Study design: it is a cross sectional study with assessment of dietary diversity and Nutritional status of adolescents studying in high school.

Setting of the study: The present study was conducted in shri Kalidas international public school Navanagar Bagalkot.

Participants: the study participants were adolescents studying $8^{\text {th }}, 9^{\text {th }}$ and $10^{\text {th }}$ standard classes in Kalidas high school of Navanagar Bagalkot district.

\section{Sampling technique}

The sample for the present study were selected by disproportionate stratified random sampling technique. 3 groups were prepared with respect to standard of class $\left(8^{\text {th }}, 9^{\text {th }}, 10^{\text {th }}\right)$. Then 40 adolescents were selected from each standard/group using lottery method. Hence the total sample selected for the study include 120 adolescents studying in Kalidas High school Bagalkot.

\section{Criteria for selection of sample}

Inclusive criteria: the study included the

1. Adolescents and their parents willing to participate in the study

2. Adolescents who are available at the time of data collection 
3. Adolescents and their parents who know to understand/read/write Kannada or English.

Exclusive criteria: the study excluded the

1. Adolescents/parents who are hospitalized and cannot provide data.

2. Adolescents/parents who are supposed to be out the study area, at the time of data Collection.

3. Adolescents/parents who are mentally challenged.

4. Adolescents with known history of chronic illness.

5. Adolescents involved in any other research study to improve the nutritional status.

Sample size estimation: In the present study the sample size was calculated by using G-power software. The sample size was estimated using the results (mean and standard deviation) of a previous similar study conducted in India. The level confidence was $95 \%(\alpha=5 \%)$ and $Z \alpha=1.96$. The power of test was considered $80 \%$. The sample size estimated was 100 . Considering $20 \%$ attritions/laps in data, 120 adolescents were enrolled in the study.

\section{Description of data collection tool}

The final format of the tool was comprised of 3 parts.

\section{Section-A Baseline proforma}

It is a structured proforma consisting 14 items regarding baseline data of the subjects.

\section{Section-B FANTA/Dietary diversity}

Food \& Nutrition technical assistance Self scoring self scale is a standardized tool was used (2020). The researcher obtained the formal permission for utilization of tool for research study from the author. The Tool consists of 09 components.1; cereals, 2 roots/tubers, 3 vegetables, 4fruits, 5 meat/poultry, 6 fish/sea, 7 milk/milk product, 8 oil/fat, and 9 sugar/ honey assessed by the use of "No" or "Yes" options.

\section{Section-C Nutritional assessment}

Nutritional status was assessed by Anthropometric measurements such as body weight and height were measured, by using a weighing scale in light clothing with no jackets or coats, shoes, an additional clothing on the nearest $0.1 \mathrm{~kg}$ on a new calibrated portable scale and the latter by using weighing machine with no shoes; shoulders, buttocks, and heels touching the vertical stand; and the head in Frankfurt position the nearest $0,1 \mathrm{~cm}$, respectively.

\section{Section-D WHO Anthro plus software}

The anthropometric data: Body weight, Height, date of birth and sex were entered to obtain the nutritional status in the form of height-for age and BMI-for-age $\mathrm{Z}$ scores by using the WHO anthro plus software.

Data collection: data collection was done from March 12 to April 03, 2021. Data collection was carried out in 3 phases- first phase: data collection regarding sociodemographic factors and their nutrition status of adolescents. Second phase: data collection regarding dietary diversity of adolescents. Third phase: data collection regarding unhealthy dietary habits of adolescents.

Statistical Analysis: The statistical analysis was carried out by SPSS version 28. Chi square test, ANOVA, Multiple linear regression analysis, Multiple Correlation Analysis were be used to determine the association between sociodemographic factors and their nutritional status of adolescents \& association between dietary diversity and their BMI for thinness of adolescents.

Ethical Consideration: Ethical clearance certificate was obtained from B.V.V.S Sajjalashree Institute of Nursing Sciences, institutional ethical committee. Written consent was obtained from each participant. 
Lakshmavva Gondi et.al. Determine dietary diversity and its relationship with nutritional status of adolescents studying in High schools of Bagalkot

\section{RESULTS}

Table No.1 Distribution of adolescents according their socio demographic factors $\mathrm{N}=120$

\begin{tabular}{|c|c|c|c|c|}
\hline S.No & Socio demographic factors & Character & Frequency & Percentage \\
\hline \multirow[t]{5}{*}{1} & \multirow[t]{5}{*}{ Age } & 13 years & 01 & $.8 \%$ \\
\hline & & 14 years & 24 & $20.0 \%$ \\
\hline & & 15 years & 57 & $47.5 \%$ \\
\hline & & 16 years & 33 & $27.5 \%$ \\
\hline & & 17years & 05 & $4.2 \%$ \\
\hline \multirow[t]{2}{*}{2} & \multirow[t]{2}{*}{ Sex } & Male & 76 & $63.3 \%$ \\
\hline & & Female & 44 & $36.7 \%$ \\
\hline \multirow[t]{3}{*}{3} & \multirow[t]{3}{*}{ Standard of learning } & $8^{\text {th }}$ & 37 & $30.8 \%$ \\
\hline & & $9^{\text {th }}$ & 47 & $39.2 \%$ \\
\hline & & $10^{\text {th }}$ & 36 & $30.0 \%$ \\
\hline \multirow[t]{2}{*}{4} & \multirow[t]{2}{*}{ Type of family } & Nuclear & 90 & $75.0 \%$ \\
\hline & & Joint & 30 & $25.0 \%$ \\
\hline \multirow[t]{2}{*}{5} & \multirow[t]{2}{*}{ Religion } & Hindu & 93 & $77.5 \%$ \\
\hline & & Muslim & 27 & $22.5 \%$ \\
\hline \multirow[t]{4}{*}{6} & \multirow[t]{4}{*}{ No of family members } & $1-4$ & 30 & $36 \%$ \\
\hline & & $5-8$ & 74 & $88.8 \%$ \\
\hline & & $9-12$ & 9 & $10.8 \%$ \\
\hline & & 13 \& above & 7 & $8.4 \%$ \\
\hline \multirow[t]{5}{*}{7} & \multirow[t]{5}{*}{ Education of the mother } & Illiterate & 24 & $20.0 \%$ \\
\hline & & Primary & 60 & $50.0 \%$ \\
\hline & & High school & 29 & $24.2 \%$ \\
\hline & & PUC\& above & 5 & $4.2 \%$ \\
\hline & & Death of parents & 11 & $9.2 \%$ \\
\hline \multirow[t]{5}{*}{8} & \multirow[t]{5}{*}{ Occupation of the mother } & Housewife & 72 & $60.0 \%$ \\
\hline & & Coolie & 39 & $32.5 \%$ \\
\hline & & Government & 3 & $2.5 \%$ \\
\hline & & Employee & & \\
\hline & & Business & 4 & $3.3 \%$ \\
\hline \multirow[t]{5}{*}{9} & \multirow[t]{5}{*}{ Education of the father } & Illiterate & 18 & $15.0 \%$ \\
\hline & & Primary & 31 & $25.8 \%$ \\
\hline & & High school & 38 & $31.7 \%$ \\
\hline & & PUC & 20 & $16.7 \%$ \\
\hline & & Graduation \& above & 4 & $3.3 \%$ \\
\hline \multirow[t]{5}{*}{10} & \multirow[t]{5}{*}{ Occupation of the father } & Unemployed & 8 & $6.7 \%$ \\
\hline & & Cooli & 82 & $68.3 \%$ \\
\hline & & Government employee & 2 & $1.7 \%$ \\
\hline & & Private employee & 8 & $6.7 \%$ \\
\hline & & Business & 11 & $9.2 \%$ \\
\hline \multirow[t]{3}{*}{11} & \multirow[t]{3}{*}{ Family monthly income } & Rs $<10,000$ & 31 & $25.8 \%$ \\
\hline & & Rs 10,000 to 20,00 & 72 & $129.3 \%$ \\
\hline & & Rs $>20,000$ & 6 & $4.9 \%$ \\
\hline \multirow[t]{2}{*}{12} & Place of residence & Rural & 15 & $12.5 \%$ \\
\hline & & Urban & 105 & $87.5 \%$ \\
\hline 13 & Attended any educational programme on dietary diversity & Yes & 8 & $6.7 \%$ \\
\hline & & No & 112 & $93.3 \% *$ \\
\hline 14 & Parents marital status & Together & 109 & $90.8 \%$ \\
\hline & & Death of parents & 11 & $9.2 \%$ \\
\hline
\end{tabular}

Table No.2 Distribution and description of adolescents according to their Nutritional status in terms of height for age $\mathbf{N}=\mathbf{1 2 0}$

\begin{tabular}{|c|c|c|c|c|}
\hline S.No & Height for Age & Z Scoring range & $\mathbf{F}$ & $\%$ \\
\hline 1. & Normal & $>-1 \mathrm{SD}$ to $+3 \mathrm{SD}$ & 70 & $58.3 \%$ \\
\hline 2. & Mild stunting & $-1 \mathrm{SD}$ to $-2 \mathrm{SD}$ & 32 & $26.7 \%$ \\
\hline 3. & Moderate stunting & $-2 \mathrm{SD}$ to $-3 \mathrm{SD}$ & 11 & $9.2 \%$ \\
\hline 4. & Severe stunting & $<-3 S D$ & 7 & $5.8 \%$ \\
\hline \multicolumn{3}{|c|}{ Total } & 120 & \\
\hline
\end{tabular}

Among 120 adolescents, 70 (58.3\%) adolescents were normal, 32 (26.7\%) had mild stunting, $11(9.2 \%)$ adolescents had moderate stunting and 7 (5.8\%) adolescents were severely stunted.
Table No.3 Distribution and description of sample according to Nutritional status with reference to BMI for age. $\quad \mathrm{N}=\mathbf{1 2 0}$

\begin{tabular}{|c|c|c|c|c|}
\hline S.NO & BMI for age & Scoring range & $\mathbf{F}$ & $\%$ \\
\hline 1. & Normal & 18.50 to 24.99 & 41 & $34.2 \%$ \\
\hline 2. & Underweight & $<18.50$ & 71 & $59.2 \%$ \\
\hline 3. & Overweight & 25 & 08 & $6.7 \%$ \\
\hline \multicolumn{3}{|c|}{ Total } & 120 & \\
\hline
\end{tabular}

Out of 120 adolescents 41 (34.2\%) adolescents were found normal, 71 (59.2\%) adolescents were underweight and08 (6.7\%) adolescents were overweight. 
Lakshmavva Gondi et.al. Determine dietary diversity and its relationship with nutritional status of adolescents studying in High schools of Bagalkot

Table No.4 Distribution of sample according to nutritional status with reference to BMI for thinness. $\mathrm{N}=120$

\begin{tabular}{|c|c|c|c|c|}
\hline S.NO & BMI FOR THINNESS & BMI scoring range & $\mathbf{F}$ & $\%$ \\
\hline 1) & Normal & $\geq 18.50$ & 48 & $40.0 \%$ \\
\hline 2) & Mild thinness & $17-18.49$ & 21 & $17.5 \%$ \\
\hline 4) & Moderate thinness & $16-16.99$ & 12 & $10.0 \%$ \\
\hline 5) & Severe thinness & $<16$ & 39 & $32.5 \%$ \\
\hline \multicolumn{3}{|c|}{ Total } & 120 & 100 \\
\hline
\end{tabular}

Out of 120 adolescents, $48(40.0 \%) \quad$ had moderate thinness, 39 adolescents were found normal, $21(17.5 \%) \quad$ adolescents had severe thinness. adolescents had mild thinness, 12 (10.0\%)

\begin{tabular}{|c|c|c|c|c|c|c|c|c|}
\hline \multirow[t]{2}{*}{ Sl.no } & \multirow[t]{2}{*}{$\begin{array}{l}\text { Socio demographic } \\
\text { Variable }\end{array}$} & \multirow[t]{2}{*}{$\begin{array}{l}\text { Chi square } \\
\text { value }\end{array}$} & \multirow[t]{2}{*}{ DF } & \multirow[t]{2}{*}{$\begin{array}{c}\mathbf{P} \\
\text { Value }\end{array}$} & \multirow[t]{2}{*}{$\begin{array}{l}\text { Odds } \\
\text { Ratio }\end{array}$} & \multicolumn{2}{|c|}{$\begin{array}{c}\text { 95\% Confidence } \\
\text { interval }\end{array}$} & \multirow{2}{*}{$\begin{array}{c}\text { Significance } \\
\text { Of } \\
\text { association }\end{array}$} \\
\hline & & & & & & Lower & Upper & \\
\hline 1 & Age & 3.510 & 4 & .476 & & - & - & NS \\
\hline 2 & Gender & 959 & 1 & .328 & 1.452 & .688 & 3.065 & NS \\
\hline 3 & Standard & 1.103 & 2 & .576 & & & & NS \\
\hline 4 & Type of family & .101 & 1 & .750 & 1.144 & .499 & 2.623 & NS \\
\hline 5 & Religion & .166 & 1 & 0.684 & .835 & .350 & 1.992 & NS \\
\hline 6 & No of family member & 10.15 & 12 & .603 & 0.86 & 0.26 & 1.12 & NS \\
\hline 7 & Education of mother & 3.234 & 4 & .520 & 1.22 & 0.36 & 1.32 & NS \\
\hline 8 & Occupation of mother & 9.730 & 4 & 0.045 & 1.16 & 0.54 & 1.86 & significant \\
\hline 9 & Education of father & 13.15 & 5 & 0.022 & 0.92 & 0.42 & 1.68 & significant \\
\hline 10 & Occupation of father & 4.060 & 5 & .549 & 0.78 & 0.41 & 1.12 & NS \\
\hline 11 & Family monthly income & 25.37 & 20 & .188 & & & & NS \\
\hline 12 & Place of residence & 121 & 1 & .728 & 1.216 & .404 & 3.660 & NS \\
\hline 13 & $\begin{array}{l}\text { Attended any educational program on } \\
\text { dietary diversity }\end{array}$ & 6.52 & 1 & .011 & 100 & .012 & .837 & Significant \\
\hline 14 & Parents marital status & 1.862 & 1 & .172 & 2.397 & 662 & 8.672 & NS \\
\hline
\end{tabular}

Table No.6 Distribution of sample based on dietary diversity.

\begin{tabular}{|c|c|c|c|c|}
\hline S no & Variable & Character & Frequency & Percentage \% \\
\hline \multirow[t]{2}{*}{ I } & \multirow[t]{2}{*}{ Cereals } & No & 3 & $2.5 \%$ \\
\hline & & Yes & 117 & $96.7 \%$ \\
\hline \multirow[t]{2}{*}{ II } & \multirow[t]{2}{*}{ Roots/tubers } & No & 41 & $33.9 \%$ \\
\hline & & Yes & 79 & $65.3 \%$ \\
\hline \multirow[t]{2}{*}{ III } & \multirow[t]{2}{*}{ Vegetables } & No & 8 & $6.6 \%$ \\
\hline & & Yes & 112 & $92.6 \%$ \\
\hline \multirow[t]{2}{*}{ IV } & \multirow[t]{2}{*}{ Fruits } & No & 3 & $2.5 \%$ \\
\hline & & Yes & 117 & $96.7 \%$ \\
\hline \multirow[t]{2}{*}{$\mathrm{V}$} & \multirow[t]{2}{*}{ Meat/poultry } & No & 42 & $34.7 \%$ \\
\hline & & Yes & 78 & $64 \%$ \\
\hline \multirow[t]{2}{*}{ VI } & \multirow[t]{2}{*}{ Fish/sea } & No & 63 & $52.1 \%$ \\
\hline & & Yes & 56 & $46.3 \%$ \\
\hline VII & Milk/milk product & Yes & 120 & $99.2 \%$ \\
\hline \multirow{2}{*}{ VIII } & \multirow{2}{*}{ Oil/fat } & No & 37 & $30.6 \%$ \\
\hline & & Yes & 83 & $68.6 \%$ \\
\hline \multirow[t]{2}{*}{ IX } & \multirow[t]{2}{*}{ Sugar/honey } & No & 8 & $6.6 \%$ \\
\hline & & Yes & 112 & $92.6 \%$ \\
\hline
\end{tabular}

Table No.8 Association between dietary diversity with nutritional status among adolescents $\mathrm{N}=\mathbf{1 2 0}$

\begin{tabular}{|c|c|c|c|c|c|c|c|c|}
\hline \multirow[t]{2}{*}{ Sl.No } & \multirow{2}{*}{$\begin{array}{c}\text { Dietary diversity } \\
\text { Variable }\end{array}$} & \multirow[t]{2}{*}{ Chi square value } & \multirow[t]{2}{*}{ DF } & \multirow{2}{*}{$\begin{array}{c}\mathbf{P} \\
\text { Value } \\
\end{array}$} & \multirow[t]{2}{*}{ Odd Ratio } & \multicolumn{2}{|c|}{$95 \% \mathrm{CI}$} & \multirow[t]{2}{*}{ Association } \\
\hline & & & & & & Lower & Upper & \\
\hline 1 & Cereals & 3.890 & 1 & .049 & 1.060 & .992 & 1.132 & NS \\
\hline 2 & Roots/tubers & .538 & 1 & .463 & .753 & .353 & 1.608 & NS \\
\hline 3 & Vegetables & 1.277 & 1 & .258 & 2.608 & .485 & 12.968 & NS \\
\hline 4 & Fruits & 2.434 & 1 & .119 & .955 & .907 & 1.006 & NS \\
\hline 5 & Meat/poultry & .312 & 1 & .576 & .807 & .380 & 1.714 & NS \\
\hline 6 & Fish/sea & 2.150 & 2 & .341 & & & & NS \\
\hline 7 & Milk/milk product & & & & & & & \\
\hline 8 & Oil/fat & .018 & 1 & .892 & 1.056 & .483 & 2.306 & NS \\
\hline 9 & Sugar/honey & .118 & 1 & .731 & .778 & .185 & 3.267 & NS \\
\hline
\end{tabular}

Logistic regression analysis was used to determine the association between dietary diversity and nutritional status of adolescents. There was no significant association $(\mathrm{P}<0.202)$ found between dietary diversity and nutritional status of adolescents. The mean sum of squares was 23.37 and the mean square residual value 
was 12.11 with sum of square 1429.10. There was no significant association (0.167) found between dietary diversity \& BMI of adolescents.

Limitations of the study: the study was confined only to determine dietary diversity and its relationship with nutritional status among adolescents. The study focused only on the adolescents and their parents selected studying in Kalidas high school of Navanagar Bagalkot.

\section{Acknowledgement: None \\ Conflict of Interest: None}

Source of Funding: None

Ethical Approval: Approved

\section{REFERENCES}

1. C. Ferron, F. Narring, M. Cauderay, P.-A. Michaud.port activity in adolescence: associations with health perceptions and experimental behaviours Health Education Research, Volume 14, Issue 2, April 1999, Pages 225-233,

2. B.M. Vashist, Joyti and M.K. Goel Nutritional Status of Adolescents In Rural And Urban Rohtak, Haryana. Health and population: perspectives and issues. HPPI, Vol. 32 (4), 2009190

3. Smitha Malenahalli Chandrashekarappa1, Narayana Murthy Mysuru

Ramakrishnaiah1, Renuka Manjunath. Nutritional status in adolescent girls: Attempt to determine its prevalence and its association with sociodemographic variables. Family Medicine and Community Health. 2018;6(4):184-190

4. Vakili M, Abedi P, Sharifi M, Hosseini M. Dietary diversity and its related factors among adolescents: a survey in Ahvaz-Iran. Glob J Health Sci. 2013 Jan 13;5(2):181-6. doi: 10.5539/gjhs.v5n2p181. PMID: 23445707; PMCID: PMC4776787.

5. Olumakaiye MF. Adolescent Girls With Low Dietary Diversity Score Are Predisposed to Iron Deficiency in Southwestern Nigeria. ICAN: Infant, Child, \& Adolescent Nutrition. 2013;5(2):85-91. doi:10.1177/1941406413475661

How to cite this article: Gondi L, Dhandargi U, Natekar DS. Determine dietary diversity and its relationship with nutritional status of adolescents studying in high schools of Bagalkot. International Journal of Science \& Healthcare Research. 2022; 7(1): 23-28. DOI: https://doi.org/10.52403/ijshr.20220105 